\title{
COMPARISON OF SEDIMENT TRANSPORT MODELS WITH IN-SITU SAND FLUX MEASUREMENTS AND BEACH MORPHODYNAMIC EVOLUTION
}

\author{
${ }^{1}$ Cartier Adrien, ${ }^{2}$ Larroudé Philippe and ${ }^{1}$ Héquette Arnaud
}

The aim of this study is to set up a procedure of linking of three codes to be able to simulate realistic coastal sediment transport and associated morphological change. In order to calibrate sediment transport formulae, comparisons of our simulations were carried out with in-situ data of sand transport measured on macrotidal beaches of northern France on the shore of the English Channel and Dover Strait. This technique of simulation was then used to compare and investigate the efficiency of several sediment transport models on the site of Sète (microtidal beach on the Mediterranean coast) during two storms events.

Keywords: Longshore sediment transport, sediment transport modeling, macrotidal beaches, storm.

\section{INTRODUCTION}

Since a few years, numerical modeling has grown substantially and is, now, largely used by the coastal scientific community. As a first step, models have to be calibrated in order to correspond, as close as possible, to natural phenomena. Thus, a major focus of nearshore research is to relate measured and predicted sediment transport to morphological change, with the aim of improving our understanding and modeling capabilities of beach morphodynamics.

This paper discusses the capabilities of numerical models to predict sediment transport and morphodynamics over sandy beds. In the first part, the sediment transport model is presented which solves the bed evolution equation in conjunction with sediment transport formulae. The flow field and the water depth are calculated using the depth-averaged hydrodynamic model TELEMAC-2D. The work consisted in setting up the methodology of calculation based on the work of De Vriend (1987), De Vriend and Stive (1987) and Smit et al. (2008). The principle is to make an external coupling of three codes where Artemis models swell propagation; Telemac2D calculates the currents and Sisyphe determined the morpho-dynamic evolution. The basic principle of this external coupling is to make this loop on the codes with a step of morpho-dynamic time depending essentially on weather conditions and on the hydrodynamic forcing of the studied beach. These models were used in the framework of a simulated meteorological cycle describing the seasonal evolution of hydrodynamic factors. The procedure for linking the three codes to be able to simulate realistic climate regimes has been already validated in terms of hydrodynamics and morphodynamic evolution (Larroudé, 2008). In order to calibrate the different sediment formulae, comparisons of our simulations were realized with in situ measurement of longshore sediment transport (LST) conducted on macrotidal beaches of the Dover Strait and eastern English Channel. In a second part, comparisons of various sediment transport formulae and their contribution on beach morphological change during two specific storms at site on the French Mediterranean coast are exposed.

\section{STUDY AREA}

The first study area (Site A) is located on the shore of the English Channel while the second one is near Sète on the French Mediterranean coast (Site B) (Figure 1).

Site A consists of 300 to $800 \mathrm{~m}$ wide dissipative macrotidal beaches characterized by extensive intertidal bar-trough systems. The first field experiment site (Wissant Bay, WI) is on the shore of the Dover Strait, while the second study site (Hardelot, HA) is located on the eastern English Channel coast. Mean sediment size is $0.22 \mathrm{~mm}$ at Wissant and $0.23 \mathrm{~mm}$ at Hardelot with, respectively, a beach slope $(\tan \beta)$ of 0.012 and 0.026 . The coasts of Northern France are exposed to relatively low-energy waves that are refracted by numerous offshore sand banks. Dominant wave directions are from southwest to west, originating from the English Channel followed by waves from the northeast to north, generated in the North Sea. Offshore modal significant wave heights are similar for all the study sites and are less than $1.5 \mathrm{~m}$, but may exceed $4 \mathrm{~m}$ during storms (Clique and Lepetit, 1986; Ruz et al., 2009). The study sites are affected by semi-diurnal tides with mean spring tide ranging from about $7 \mathrm{~m}$ at Wissant to almost $10 \mathrm{~m}$ at Hardelot. High tidal range is responsible for relatively strong tidal currents that flow almost parallel to the shoreline in the coastal zone. Due to a flood-dominated asymmetry, dominance of flood currents, combined with a system of winds and swells from the SW, generates a hydrodynamic circulation and a littoral drift directed eastward on the coast of the North Sea and northward on the shore of the Channel (Sipka and Anthony, 1999; Héquette et al., 2008). Recent 
studies have shown, notwithstanding, that tidal currents alone can not be responsible for high sediment flux in the intertidal zone, even where the tidal range reaches nearly $10 \mathrm{~m}$ especially during fair weather conditions (Cartier, 2011).

Site B is a microtidal, swell-dominated coastal environment characterized by a linear beach of about $2.5 \mathrm{~km}$ length. The mean near shore bed slope is 0.04 , while the median grain size in the surf zone is $0.25 \mathrm{~mm}$. Mean significant offshore wave height is about $1.5 \mathrm{~m}$ increasing to $3-6 \mathrm{~m}$ during storms, while the predominant wave direction is from SSE with occasional SE swells. There is no significant seasonal variation in the offshore wave climate. Certain and Barusseau (2006) showed that the morphodynamic evolution of offshore bars in a microtidal environment and bimodal moderate wave regime follows two different conceptual models, the main one being a seasonal pattern in line with the observed cycle of hydrodynamic conditions (Certain, 2002).

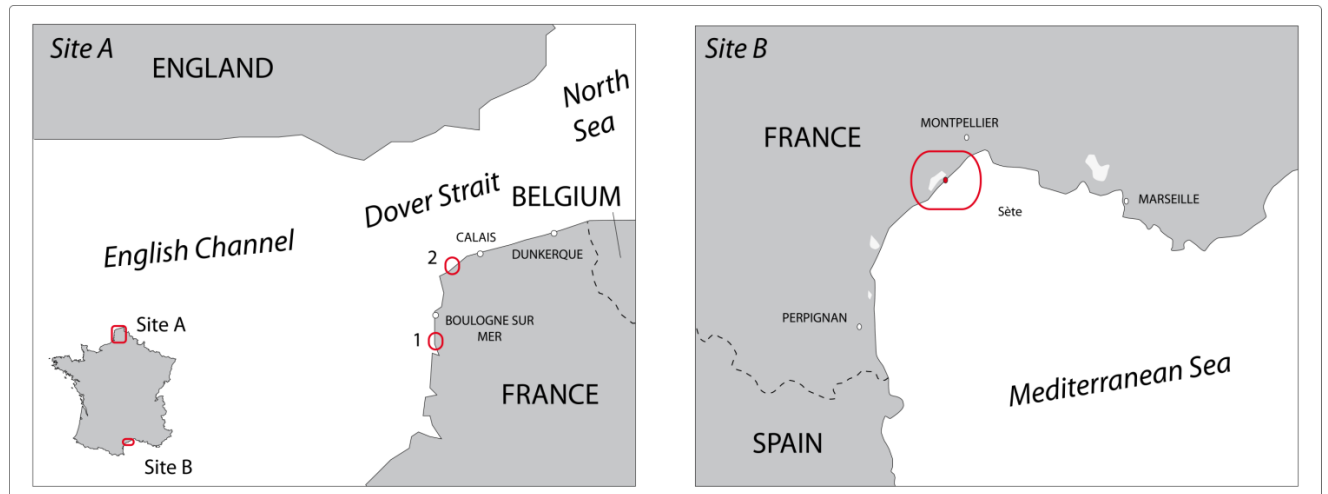

Figure 1: Location of the field sites along the coast of Northern France (Site A): 1) Hardelot Beach, 2) Wissant Bay and on the Mediterranean coast (site B)

\section{METHODOLOGY}

Field methodology

Site A: Longshore sediment fluxes were estimated using streamer traps, following the method proposed by Kraus (1987). The sediment traps consisted of a vertical array of five individual streamer traps with $63 \mu \mathrm{m}$ mesh size sieve cloth that collects sand-size particles at different elevations above the bed. First streamer trap (F5) is located $0.05 \mathrm{~m}$ above the bed and the last one (F1) is at approximately $0.90 \mathrm{~m}$ (Figure 2B). Traps were positioned so that the streamer mouths faced the longshore current visually determined by the operators (Figure 2A). Measurements of longshore sediment transport with the sediment traps were undertaken during 10 minutes. Calculations of the sediment flux from sand traps were carried out according to the procedure of Rosati and Kraus (1989). Sediment flux at a streamer trap $\mathrm{Q}(\mathrm{f})$ is expressed in kg.s-1.m-2, while the depth integrated flux (Q) is in kg.s-1.m-1. Sediment transport measurements were typically conducted during a half tidal cycle (6h) and only exceptionally during a full tidal cycle (12h). Five LST measurements were generally carried out through a half tidal cycle on different location across the intertidal zone (Figure 2C). Current meters were also deployed on the foreshore. The instruments were routinely placed on the outer side of intertidal bars. Three instruments were used; an ADCP (Acoustic Doppler Current Profiler) with pressure sensor, a S4 ADW Interocean and a Midas Valeport electromagnetic current meters (Figure $2 \mathrm{C}, 2 \mathrm{D}$ and $2 \mathrm{E}$ ). These instruments were programmed to measure wave and current parameters at a frequency of $2 \mathrm{~Hz}$ during 9 minute bursts every 15 minutes, yielding values of significant wave height $(\mathrm{Hs})$, period and direction, and mean near-bottom current speed and direction.

Morphological monitoring of each studied zone was carried out every sampling day using a high precision DGPS. For more details about the field methodology and data acquisition, see Cartier and Héquette (2011).

Site B: Hydrodynamic measurements were made along a cross-shore transect. Different instruments have been deployed from the 15 of December 2008 to 25 of February 2009 cumulating 73 days of observation. The equipment is constituted by 3 Nortek ADV (Acoustic Doppler Velocimeter) with pressure sensor), 2 RDI $600 \mathrm{kHz}$ bottom mounted ADCP and an electromagnetic current meter and pressure sensor (S4DW Interocean). The cross-shore instruments transect is constituted by four locations at, approximately, $65 \mathrm{~m}, 95 \mathrm{~m}, 185 \mathrm{~m}, 600 \mathrm{~m}$ of distance from the beach. These correspond to water depth of $3.15 \mathrm{~m}, 3.45 \mathrm{~m}, 2.75 \mathrm{~m}$ and $4 \mathrm{~m}$. The different instrument locations have been chosen related to the sand bar system. 

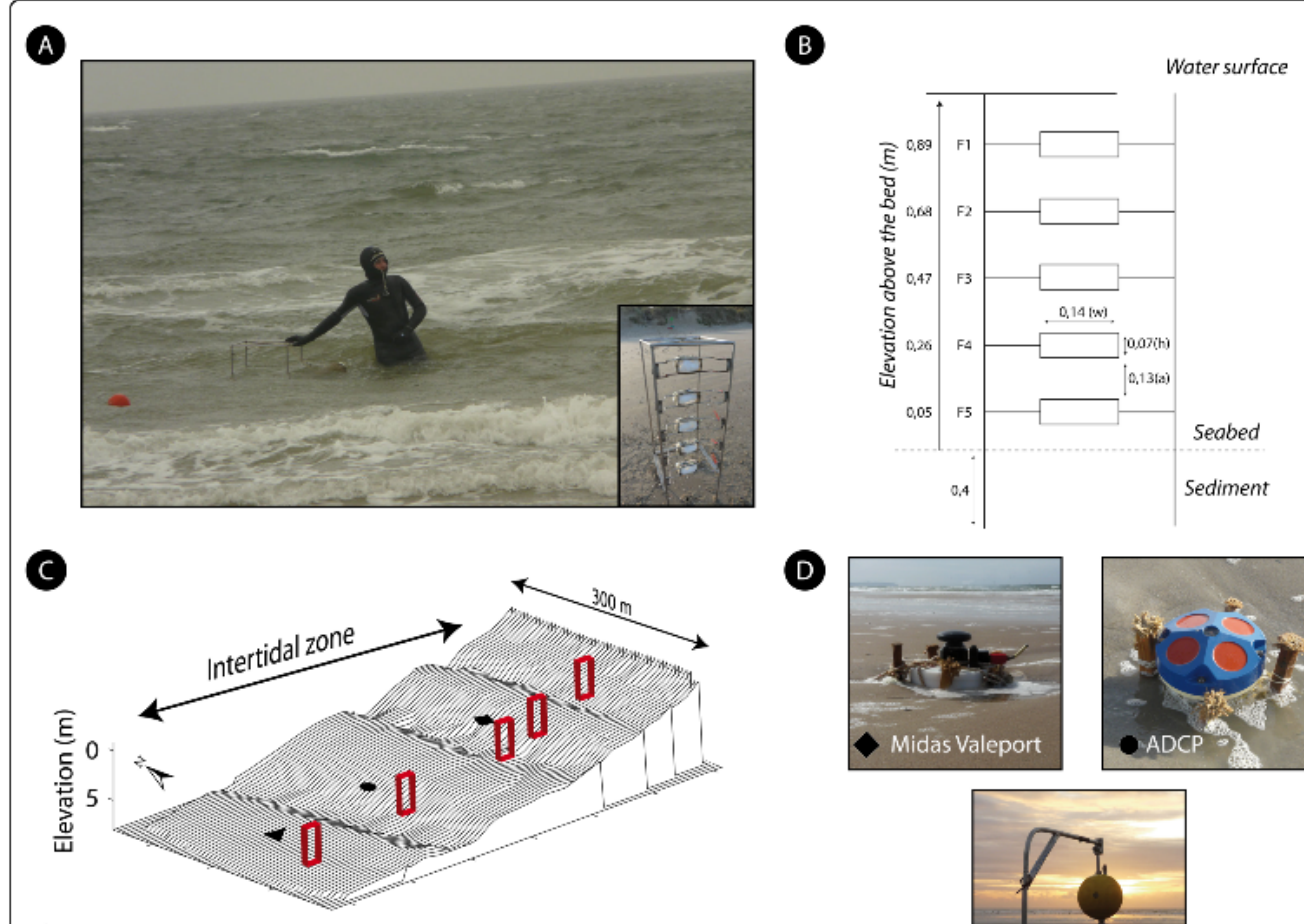

(D)
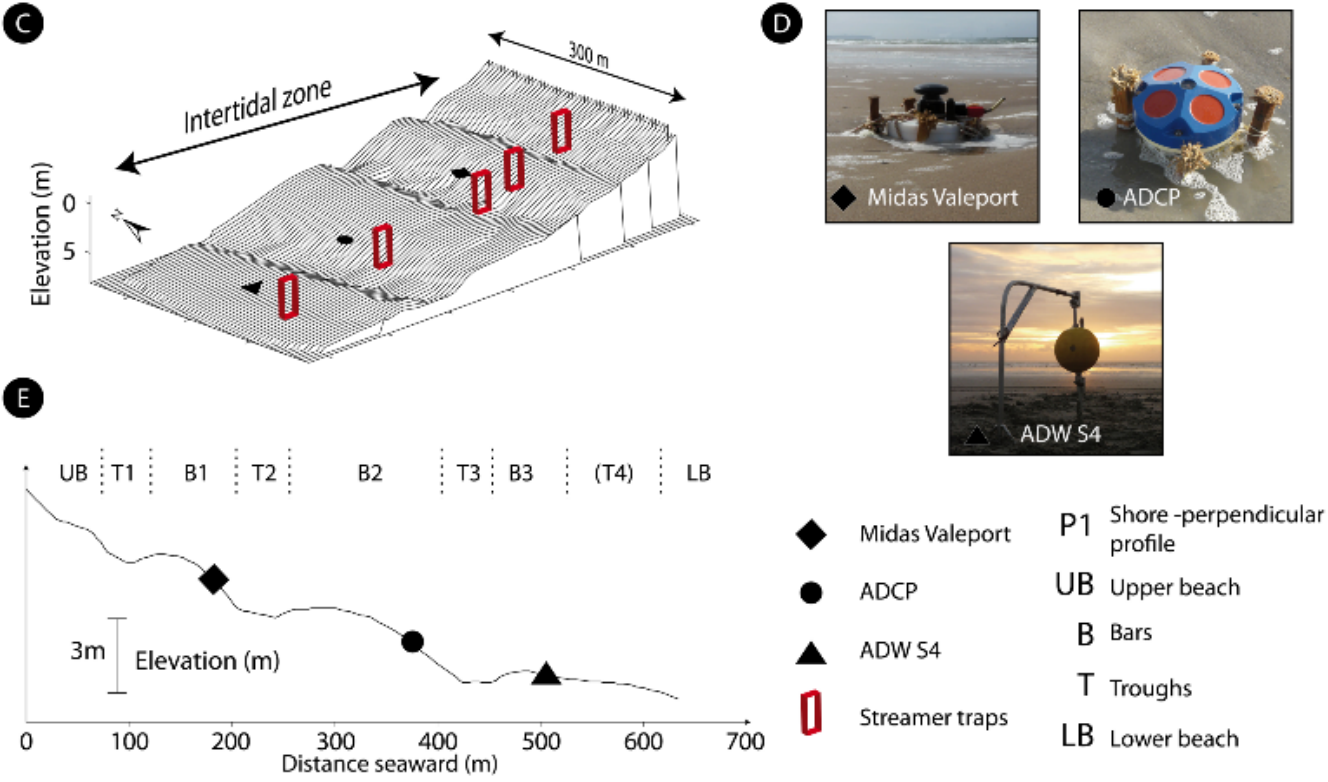

Figure 2: Field methodology. A) In situ measurements of longshore sediment transport during low to moderate wave energy conditions. B) Streamer traps device similar to those designed by Kraus (1987). C) Sediment trap deployment along a shore-perpendicular transect. D) In situ deployment of the wave and current meters. E) Shore-perpendicular profile showing the location of the hydrographical instruments. Codes refer to beach morphology where UB and LB are upper and lower beach respectively; B and T correspond to bars and troughs. Elevations are relative to the French topographic datum (IGN69).

\section{Model and methodology}

The morphological evolution in the near shore region, including its large-scale features, was first investigated using a commercial 2DH model (Camenen and Larroudé, 2003). Simulation of the wavedriven currents was carried out with Telemac2D, a finite elements model, and the Sisyphe sand transport module served to compute sediment transport rates and bed evolution. This methodology of morphodynamic modeling for sandy beaches was already improved in terms of mesh, time step and convergence in Camenen (2002), Larroudé and Camenen (2004) and in Falquès et al. (2008) and Larroudé (2008).

Sedimentary evolution is modeled under the action of the oblique incident waves and is coupled with different numerical tools dedicated to the other process involved in the near shore zone. We can mention the following modules (Figure 3):

- The wave module takes into account the surge energy dissipation (hyperbolic equation of extended Berkhoff). The Artemis code (Agitation and Refraction with Telemac2d on a MIld Slope) solves the Berkhoff equation taken from Navier-Stokes equations with some other hypotheses (small wave steepness of the surface wave, small slope...). The main results are, for every node of the mesh, the height, the phase and the incidence of the waves. Artemis can take into account the reflection and the refraction of waves on an obstacle, the bottom friction and the breakers. One of the difficulties with Artemis is that a fine mesh must be used to have good results whereas Telemac2d does not need such a fine mesh.

- The hydrodynamic module calculates currents induced by means of the surge of the waves, from the concept of radiation constraints obtained according to the module of waves. Telemac2d is designed 
to simulate the free surface flow of water in coastal areas or in rivers. This code solves Barre SaintVenant equations taken from Navier-Stokes equations vertically averaged. Then, the main results are, for every node of the mesh, the water depth and the velocity averaged over the depth. Telemac $2 \mathrm{~d}$ is able to represent the following physical phenomena: propagation of long periodic waves, including non-linear effects, wetting and drying of intertidal zone, bed friction, turbulence etc.

- The sedimentary module integrates the combined actions of the waves and the wave currents (2D or 3D) on the transport of sediment (Hervouet, 2007). The Sisyphe code solves the bottom evolution equation which expresses the mass conservation by directly using a current field result file given by Telemac2d. Several of the most currently empirical or semi-empirical formulae are already integrated in Sisyphe.

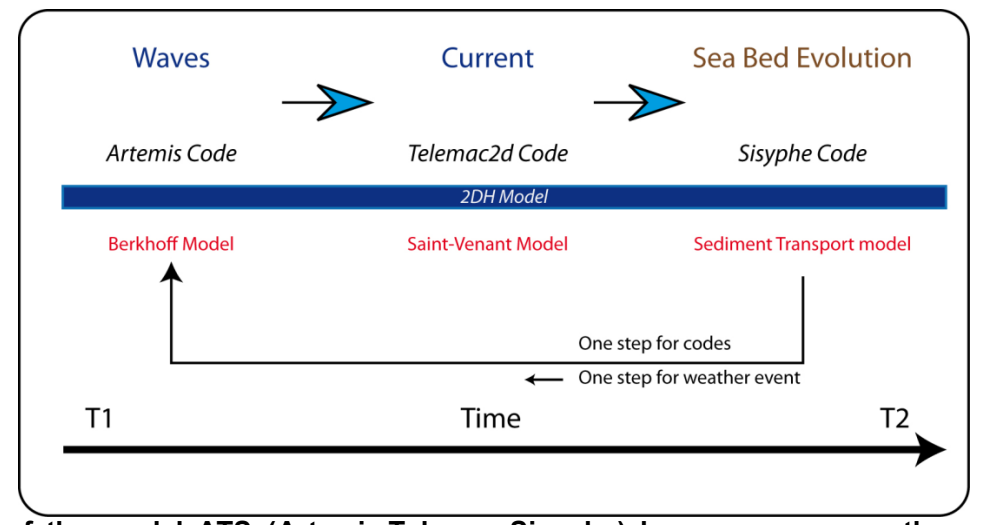

Figure 3: Diagram of the model ATS (Artemis-Telemac-Sisyphe) loop over one weather event time step (between $\mathrm{t} 1$ and $\mathrm{t} 2$ ) used for our simulations.

We set up a procedure to use the coupled codes Artemis-Telemac2d-Sisyphe and more particularly we improved the treatment of the boundary conditions in order to be able to work on fields of calculations close to the coastal zone and equivalents in dimension for the three codes. The wave module grid is the same as the flow and morphodynamic grid. The waves are incidents on both the lateral and seaward boundaries of the grid. The lateral boundaries of the flow model are defined as zero water levels.

\section{RESULTS}

\section{In situ measurements against calculated values}

Parameterization: Before using the ATS model, in situ measurements were first compared with each sediment transport formula using all the physical parameters measured in the field. Results of the calculations have been compared with other computations from several studies which also estimated sand fluxes. Longshore sediment transport rates have been modeled using Bijker formula (Bijker, 1968) (BI68), Bailard formula (Bailard, 1981) (BA81), Dibajnia and Watanabe formula (Dibajania and Watanabe, 1992) (DW92), a coupling of Van Rijn formula (Van Rijn, 1993) with an expression modeling the transport in suspension (Soulsby, 1997), this coupling being called the Soulsby-Van Rijn formula (SVR97) and Ribberink formula (Ribberink and Chen, 1993) (R93). Readers that are interested by more details on these comparisons can refer to Camenen and Larroudé (2003). Results showed that sediment transport rates measured on macrotidal beaches (Cartier) are mainly overestimated (Figure 4). However, computations from the other studies can be very close to the in situ measurements which might be due to empirical calibrations of the sediment transport formulae. According to most of the authors, their formulae give results very close to their own experimental data (Camenen and Larroudé, 2003). For example, in situ measurements in Dibajania and Watanabe (1992) have been used to calibrate DW92 formula explaining why correlations are better. It clearly appears that the range of our measurements is larger than in others studies, indicating that energy conditions during our field experiments were very variable. Camenen and Larroudé (2003) have already underlined that some formulae under- or overestimate sediment transport rates for specific hydrodynamic conditions. Ribberink formula, for example, gives good results in case of wave-current interaction but underestimates sand transport for the cases with strong currents involving high suspended load. Camenen and Larroudé (2003) highlighted that Ribberink formula is only adjusted for cases with bed load and sheet flow (without suspension) explaining why sand fluxes can be underestimated.

Large variations in wave energy conditions and sediment transport formulae that are not designed for macrotidal environments underline the need to simulate sediment fluxes more accurately using different solutions. 


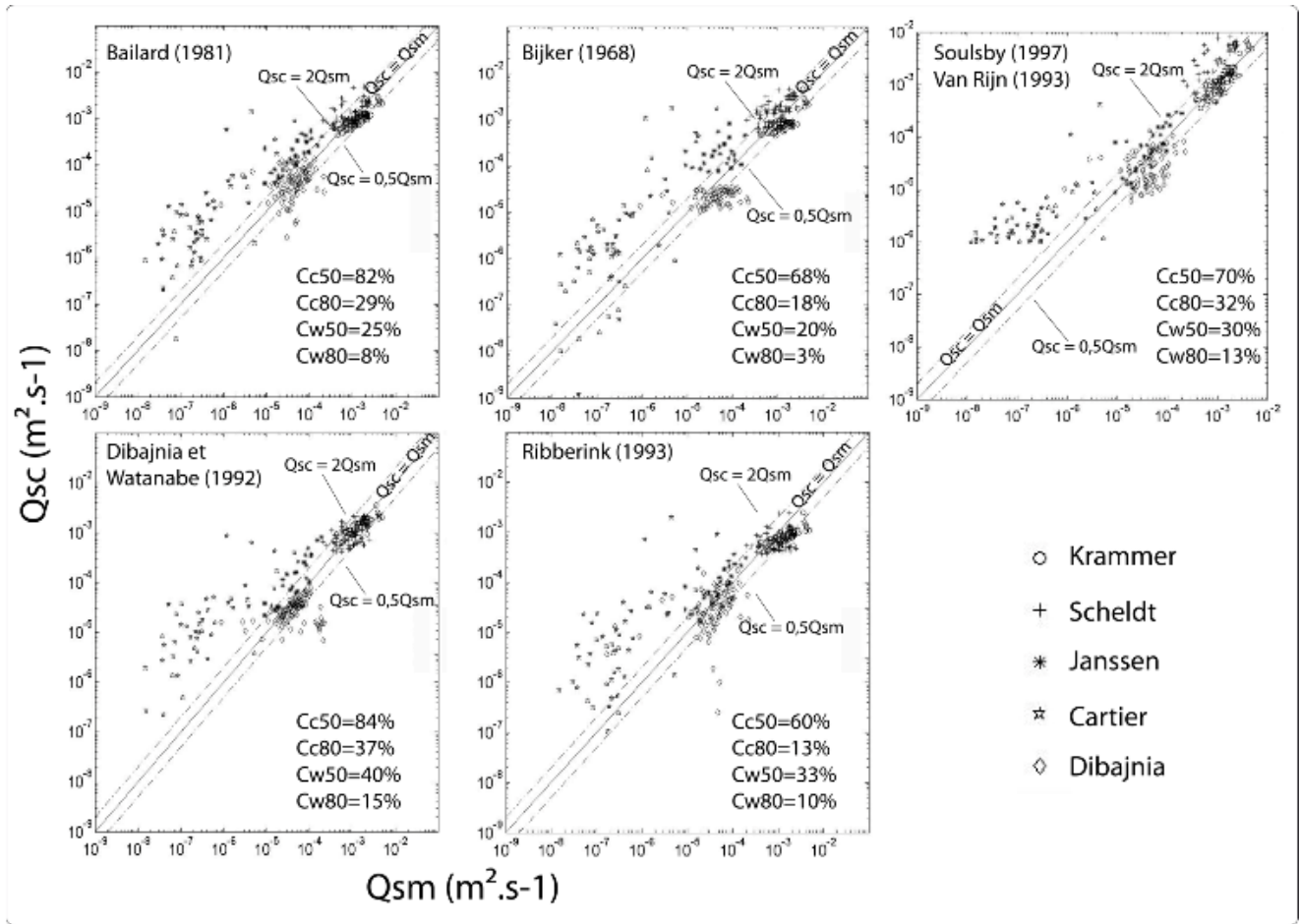

Figure 4 : Comparisons between calculated values $\left(Q_{s c}\right)$ and experimental data $\left(Q_{s m}\right)$ (Voogt et al., 1991; Dibajania and Watanabe, 1992; Dohmen - Janssen, 1999). Cartier refers to the present study. For each comparison with a given formula, the percentage of points with less than $50 \%$ error and less than $20 \%$ error is also computed for current only as well as for wave and current (Cc50, $\mathrm{Cc80}, \mathrm{Cw}_{\mathrm{w}} 50$ and $\mathrm{Cw} 80$, respectively)

\section{Results from Artemis - Telemac 2D - Sisyphe (ATS) modeling}

Several simplifications had to be admitted in ATS modeling in order to shorten computation time. Initial bathymetry, which corresponds to a digital elevation model (DEM) of the beach, is unique for each field experiment. Horizontal and vertical translation of the water level and tidal currents are not included in the modeling procedure either. Sediment flux measurements were performed in water depths between approximately $1 \mathrm{~m}$ and $1.5 \mathrm{~m}$, but because of the excursion of the tide, these measurements were made at several locations on the foreshore (Figure 2). Computed sediment loads were initially sediment fluxes modeled in the middle of the digital domain. But because the water level in the middle of the simulated field rarely matches the exact water level measured during sampling, a test was carried out to assess the potential effects of water depth on computed sediment flux using the data measured during the two field experiments at Hardelot beach (2009 and 2010).

Using Bijker formula, the following figure (Figure 5) illustrates the control of water level on the accuracy of modeled flux. It appears that correlations become better with water depth decrease, similar observations having been observed for the other formulations. The results show that sediment fluxes tend to be better estimated with decreasing water depth, which is consistent with the depths at which measurements were made. Above $1.50 \mathrm{~m}$ depth, sediment transport rates are overestimated especially for sediment transport rates lower than $10^{-3} \mathrm{~kg} \cdot \mathrm{s}^{-1} \cdot \mathrm{m}^{-1}$, while they are underestimated for water depths lower than $0.50 \mathrm{~m}$. Best results are obtained for a water depth of $0.91 \mathrm{~m}$ where percentage of acceptable values reaches $32 \%$. As soon as the water level is similar to that of measurement at the time of trapping $(1.50 \mathrm{~m})$, the distribution of points tends to align the right $Q_{s c}=Q_{s m}$. Conversely, the RMS errors are quite high when the water level is far from the actual water depth (Figure 5)

The water level acts directly on the current profile and associated sediment transport mechanisms. Thus, when the water column is higher than that at the time of measurement, the transport in suspension is favoured in the modeling, leading to an overestimation of the integrated flux in the water column. In contrast, a shallower water column could lead to higher sediment fluxes due to increased bed shear. However, it appears that the formulae are struggling to express sediment transport in very shallow water.

In accordance with these results, water levels were calibrated to be as close as possible to the in situ measurements and then, sediment fluxes have been compared with the Bijker formula (BI68) and Soulsby-Van Rijn formula (SVR97). Comparisons with other formulations cited previously are not presented because they did not provide significant results.

The results were analyzed according to the study site and the mathematical expression used. The results are better on the site of Hardelot for both formulae, the error $\mathrm{S}_{\mathrm{rms}}$ being less than 1.0 with a 
minimum of 0.53 with SVR97 (Figure 6). Moreover, the percentage of significant values reaches $32 \%$ and $46 \%$ for SVR97 and BI68, respectively. On the site of Wissant, it does not exceed 30\% whatever the formula. RMS errors are associated with a greater dispersion of data readily observable in the graphs (Figure 6). When considering all the data, the formula for SVR97 is the expression that is most satisfactory with a $\mathrm{S}_{\mathrm{rms}}$ of only 1.04 and $36 \%$ of acceptable values. The proportion of sediment flux of low intensities $\left(<1 \times 10^{-3} \mathrm{~kg} \cdot \mathrm{s}^{-1} \cdot \mathrm{m}^{-1}\right)$ is higher during the campaigns carried out in Hardelot than those held in Wissant. Conversely, the flux measurements acquired during the field investigations in the Bay of Wissant proved to be higher. Morphological changes were also more significant in Wissant than during the campaigns conducted in Hardelot

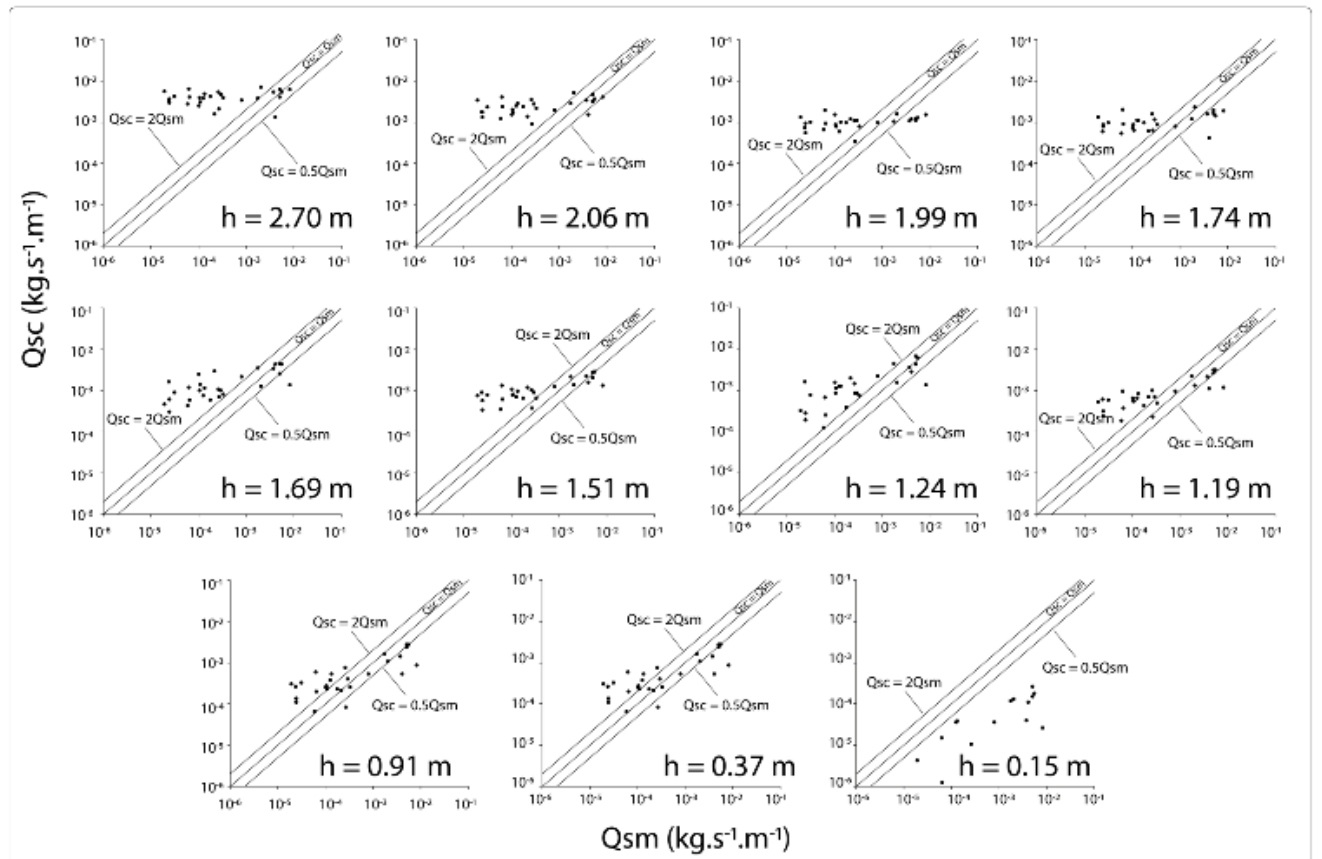

Figure 5 : Potential effect of the water depth on sediment transport rates using Bijker formula. $Q_{s c}$ refers to the calculated values while $Q_{\mathrm{sm}}$ corresponds to the measurements.

Results obtained in a previous study by Camenen and Larroudé (2003) showed that the Bijker formula generally tends to underestimate sediment transport when there is interaction of waves and current, which is generally the case in the coastal zone. In this formula, the swell is considered to be the only mechanism responsible for suspending sediment. Therefore, when wave height is low, the simulated sediment transport remains insignificant even if the average current velocity is high. Although the strength of currents in the intertidal zone is usually related to the conditions of agitation, it may sometimes be forced by wind or induced by the combination of tidal currents and those generated by the incident swell (Sedrati and Anthony, 2007). The suspended particles are then provided by currents and waves. Our results show, however, that the higher sediment fluxes $\left(>1 \times 10^{-3} \mathrm{~kg} \cdot \mathrm{s}^{-1} \cdot \mathrm{m}^{-}\right.$ ${ }^{1}$ ) are underestimated, which may be due to low wave height and mean current that are powerful enough to induce substantial sediment transport, which cannot be modeled by this expression. Conversely, the lowest sediment transport rates occur when the swell and the mean current are of low intensity. The direction of tidal currents is also directly involved in the magnitude of the sediment flux since it can easily reduce or conversely increase wave-induced currents, depending on the phase of the tidal cycle and the direction of the longshore current. Such types of case are not considered in the model, however, which may explain a part of the variability observed between measured and computed sediment fluxes.

The formula of Soulsby-Van Rijn takes into account many physical parameters for estimating the bed load and suspended load. Even though the calculations are more complicated and time consuming, the estimate is generally better, but significant errors may occur when the wave direction is opposite to that of the current (Camenen and Larroudé, 2000).

In this study, the results are particularly satisfactory for the data obtained during the field experiments at Hardelot (Figure 6) where beach morphology changes were more limited than at Wissant. When taking into account all values, it clearly appears that the most significant fluxes can nevertheless be largely underestimated since some values may be up to four times lower than the measured transport rates. During high wave energy conditions, beach morphology and bed roughness change rapidly due to an increase in bed load sediment transport. The impact of these bottom changes 
on the distribution of sediment in the water column is crucial and plays an important role in the mechanisms of suspended sediment transport. Because bed roughness is variable, largely depending on the local morphology of the beach, it is necessary to incorporate changes in beach morphology in the process of calculation which has not been done yet in this first attempt to model longshore transport on macrotidal beaches.

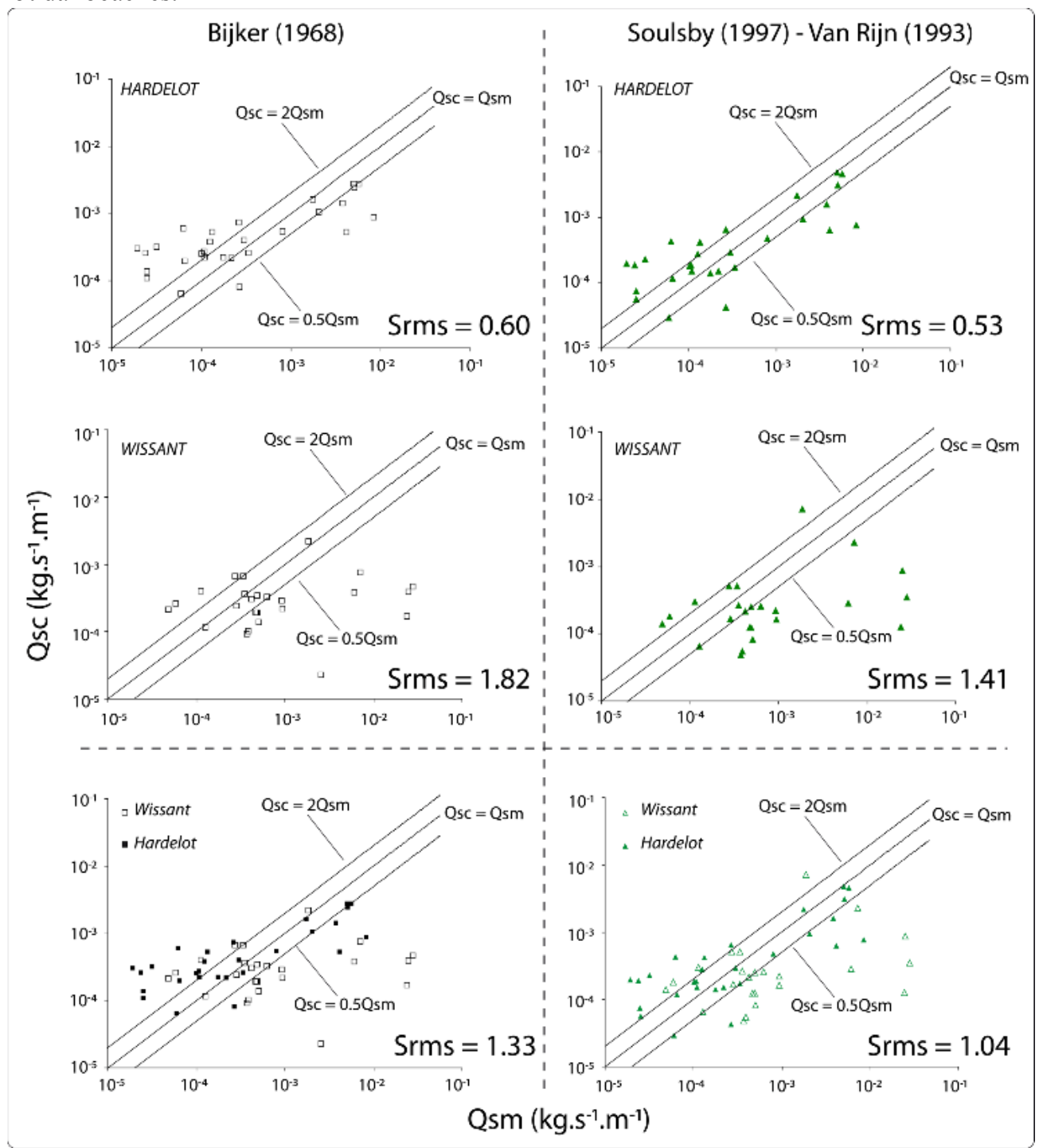

Figure 6 : Comparisons between in situ $\left(Q_{s m}\right)$ sand transport rates measured during HA09, HA10, W109 and WI10, with calculated sediment fluxes $\left(Q_{s c}\right)$ following Bijker and Soulsby - Van Rijn formulae.

\section{Beach morphology evolution}

In order to simulate beach morphology under the action of extreme events, hydrodynamic simplified models (called Multi1DH) have been used as a replacement of the 2DH model. Telemac 2D is actually not able to simulate cross shore current responsible for cross shore movement of sediment. Multi 1DH uses the following assumptions: a random wave approach and a 1DH (cross-shore) direction. An offshore wave model (shoaling + bottom friction + wave asymmetry) is used with the break point estimation. The waves in the surf zone are modeled with the classic model of Svendsen (1984) with an undertow model (Dally et al., 1984; Svendsen, 1984). The longshore current model is the Longuet-Higgins (1970). The model is included in the Sisyphe code to calculate the sea bed evolution with several sediment transport formulae.

Results concern the abilities of the ATS model to simulate sand bar movements on the beach of Sète (Site A, Figure 1) focusing on the month of December 2008 and February 2009. During these months, two similar storms in terms of significant wave height and period occurred, but in December the outer bar moved offshore and during the storm of February this outer bar moved ons hore (Figure 7, $\mathrm{A}$ and $\mathrm{B})$.

In the case of the February storm, the model reproduces very well the onshore migration of the bar with all the sediment transport formulae (Figure 7, D). On the opposite, the offshore migration that 
took place during the December storm is not so well simulated, but the results seem to be acceptable (Figure 7, C). For the 2DH model ATS, the modeling of the cross shore current (undertow) is missing. The results for both storms are thus not well representative as the model failed in simulating the crossshore migration of these sand bars.

Our results show that the different formulae of transport did not correctly reproduce the real beach morphology. During the storm of February, onshore displacement of the inner bar was not simulated by the majority of formulae. We can see through this case that the Bijker formula overestimates sediment transport, while the other formulae underestimate it. The modeling of the December storm, however, shows that some formulae are more robust than others, the formula of Ribberink being the least robust. For the same storm, the Bijker formula seems to overestimate the sediment transport, while the Bailard formula coded in the Sisyphe code has a tendency to underestimate the sediment flux for currents with high velocities.

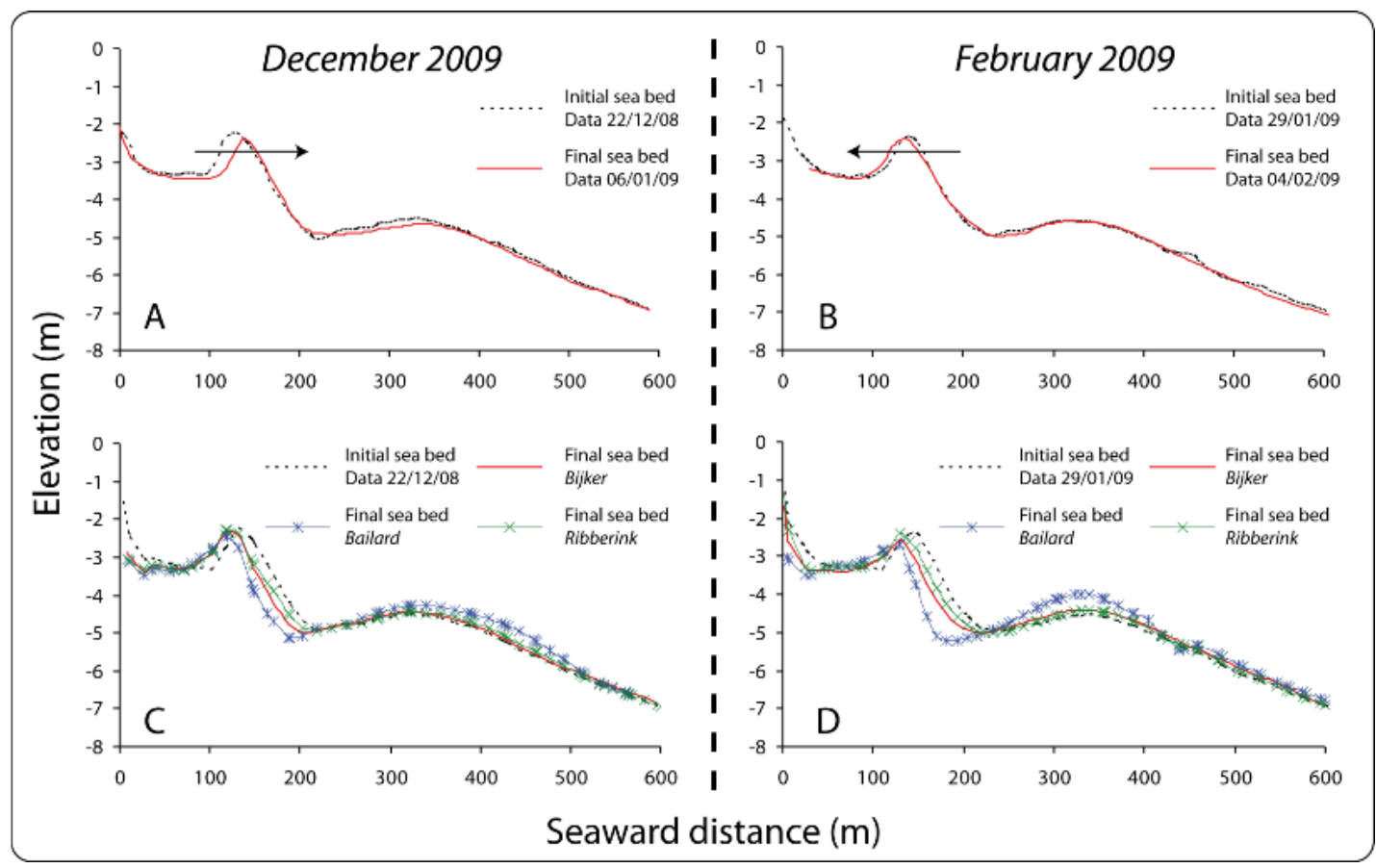

Figure 7 : Morphodynamic evolution at site 1 in December 2008 based on: (A) in situ measurements (initial bathymetry in black) and (C) simplified model Multi1DH and several sediment transport formulae, and in February 2009: (B) in situ measurements (initial bathymetry in black) and (D) simplified model Multi1DH and several sediment transport formulae

\section{CONCLUSIONS}

Despite several simplifications in the modeling procedure, comparisons of longshore sediment transport fluxes measured on sandy macrotidal beaches with computed sand fluxes gave encouraging results. It was shown that water depth is one of the major parameter affecting modeled sediment transport rates, as calculated sand fluxes were more comparable with in situ measurements when simulated water depth was similar to the actual water depth measured in the field. The height of the water column therefore represents a key term to consider in modeling sediment transport on these beaches. The best modeling results were obtained with the data collected during low energy conditions at Hardelot beach where the beach morphology was the most stable. A limitation of the modeling approach used in this study is related to the fact that beach morphology changes are not taken into account in the calculations, which should be considered in future modeling studies. Because sediment traps mainly collect sediments transported in suspension, future investigations using this data set will be aimed at de-coupling suspended and near bed load transport calculation in the different sediment transport formulae in order to evaluate only the suspended sediment flux, which should result in more accurate comparisons between modeled and measured sediment transport rates.

All these calibrations will be used to improve modeling of beach morphology evolution. Our methodology of simulation and the complementarily of both models allowed us to test the various configuration of storms to understand the results derived from the in-situ data. Although some formulae simulate relatively well onshore migration of sand bar, offshore movement is still difficult to model. 


\section{ACKNOWLEDGEMENTS}

This work was supported by French Research National Agency (ANR) through the Vulnerability Milieu and Climate program (project VULSACO, $\mathrm{n}^{\circ}$ ANR-06-VMC-009) and by the French Centre National de la Recherche Scientifique (CNRS) through the PLAMAR and MICROLIT projects of the Programme "Relief de la Terre". Additional funding was provided by the "Syndicat Mixte de la Côte d'Opale" through a doctoral scholarship to Adrien Cartier. The authors would like to thank Aurélie Maspataud, Vincent Sipka and Antoine Tresca as well as all the students and permanent staff for their help during the field experiments.

\section{REFERENCES}

Bailard, J., 1981. An energetics total load sediment transport model for a plane sloping beach. Journal of Geophysical Research 86, 10398 - 10954.

Bijker, E., 1968. Littoral drift as function of waves and current. Coastal Engineering Conference Proceedings. London, UK. 415 - 435

Camenen, B., 2002. Modélisation numérique du transport sédimentaire sur une plage sableuse, Grenoble. Phd Thesis. University of Joseph Fourrier.

Camenen, B., Larroudé, P., 2000. Numerical comparison of sediment transport formulae. Proceedings of Sandwave Dynamics Workshop. Lille, France. 37 - 42

Camenen, B., Larroudé, P., 2003. Comparison of sediment transport formulae for the coastal environment. Coastal Engineering 48, 111 - 132.

Cartier, A., Héquette, A., 2011. Estimation of longshore and cross shore sediment transport on sandy macrotidal beaches of Northern France. Proceedings of Coastal sediments'11. Miami, Florida, USA. 2130 - 2143

Cartier, A., 2011. Evaluation des flux sédimentaires sur le littoral du Nord Pas-de-Calais: Vers une meilleure compréhension de la morphodynamique des plages macrotidales. Phd Thesis. University of Littoral Côte d'Opale. Dunkerque. 407 p.

Certain, R., 2002. Morphodynamique d'une côte sableuse microtidale à barres : le golfe du Lion (Languedoc-Roussillon). Phd Thesis. University of Perpignan, p. 199.

Certain, R., Barusseau, 2006. Conceptual modelling of straight sand bars morphodynamics for a microtidal beach (Gulf of Lions, France). Proceedings of ICCE San Diego.

Clique, P.M., Lepetit, J.P., 1986. Catalogue sédimentologique des côtes françaises, côtes de la mer du Nord et de la Manche.

Dally, W.R., Dean, J.L., Dalrymple, R.A., 1984. A model for breaker decay on beaches. Proceedings of 19th Coastal Engineering Conference. 82 - 88

De Vriend, H.G., 1987. 2DH mathematical modelling of morphological evolutions in shallow water. Coastal Engineering 11, 1 - 27.

De Vriend, H.G., Stive, M.J.F., 1987. Quasi 3D modelling of nearshore currents. Coastal Engineering 11, 565 - 601.

Dibajania, M., Watanabe, A., 1992. Sheet flow under nonlinear waves and currents. Coastal Engineering, 2015 - 2029.

Dohmen - Janssen, M., 1999. Grain size influence on sediment transport in oscillatory sheet flow, phase-lags and mobile-bed effects. PhD thesis, Delft University of Technology, The Netherlands.

Falquès, A., Dodd, N., Garnier, R., Ribas, F., McHardy, L.C., Sancho, F., Larroudé, P., Calvete, D., 2008. Rhythmic surf zone bars and morphodynamic self-organization. Coastal Engineering 55, 622 - 641.

Héquette, A., Hemdane, Y., Anthony, E.J., 2008. Sediment transport under wave and current combined flows on a tide-dominated shoreface, northern coast of France. Marine geology 249, 226-242.

Hervouet, J.M., 2007. Hydrodynamics of Free Surface Flows: Modelling With the Finite Element Method. John Wiley \& Sons.

Kraus, N.C., 1987. Application of portable traps for obtaining point measurements of sediment transport rates in the surf zone. Journal of Coastal Research 3, 139-152.

Larroudé, P., 2008. Methodology of seasonal morphological modelisation for nourishment strategies on a Mediterranean beach. Marine Pollution Bulletin 67, 45 - 52. 
Larroudé, P., Camenen, B., 2004. 2DH and multi1DH morphological model for medium term evolution of large scale features and nourishment in the nearshore region: application to TrucVert and Corniche beach (France) and la Barrosa beach (Spain). Proceedings of 29th International Conference on Coastal Engineering. Lisbon.

Longuet-Higgins, M.S., 1970. Longshore currents generated by obliquely Incident waves 1. Journal of Geophysical Research 75, 6778 - 6789.

Ribberink, J., Chen, Z., 1993. Sediment transport of fine sand under asymmetric oscillatory flow. Delft Hydraulics, Report H840, Part VII, The Netherlands.

Rosati, J.D., Kraus, N.C., 1989. Development of a portable sand trap for use in the nearshore. Department of the army, U.S. Corps of Engineers. Technical report CERC 89-91, 181.

Ruz, M.-H., Héquette, A., Maspataud, A., 2009. Identifying forcing conditions responsible for foredune erosion on the northern coast of France. Journal of coastal Research, Special Issue, 356 - 360.

Sedrati, M., Anthony, E.J., 2007. Storm-generated morphological change and longshore sand transport in the intertidal zone of a multi-barred macrotidal beach. Marine geology 244, 209-229.

Sipka, V., Anthony, E.J., 1999. Morphology and Hydrodynamics of a macrotidal ridge and runnel beach under modal low conditions. Journal de Recherche Océanographique 24, 25-31.

Smit, M.W.J., Reniers, A.J.H.M., Ruessink, B.G., Roelvink, J.A., 2008. The morphological response of a nearshore double sandbar system to constant wave forcing. Coastal Engineering 55, 761 - 770.

Soulsby, R., 1997. Dynamics of marine sands, a manual for practical applications. Thomas Telford, Wallingford, England.

Svendsen, I.A., 1984. Mass flux and undertow in the surf zone. Coastal Engineering 8, 347365.

Van Rijn, L.C., 1993. Manual sediment transport measurements. Publ. Aqua Publications, Zwolle, the Netherlands, Publ. Aqua Publications, Zwolle, the Netherlands.

Voogt, L., Van Rijn, L.C., Van der Berg, J., 1991. Sediment transport of fine sand at height velocities. Journal of Hydrology Engineering 117, 869 - 890. 